\title{
An attempt to impart engineering drawing standards through problem based learning approach
}

\author{
Shreeshail M. L. ${ }^{1}$, Suresh H. K. ${ }^{2}$, Gurupadayya Hiremath ${ }^{3}$, Balachandra S. Halemani ${ }^{3}$, B. B. Kotturshettar ${ }^{4}$ \\ ${ }^{1,3}$ Assistant Professor, School of Mechanical Engineering, KLE Technological University, Hubli, Karnataka - 580031, India. \\ ${ }^{2}$ Assistant Professor, Department of Mechanical Engineering, B.V. Bhoomaraddi College of Engineering and Technology, \\ Hubli, Karnataka - 580031, India. \\ ${ }^{4}$ Professor and Head, School of Mechanical Engineering, KLE Technological University, Hubli, Karnataka - 580031, India. \\ ${ }^{1}$ shreeshail_m@kletech.ac.in
}

\begin{abstract}
Engineering drawing courses need to address the student's expectations and maintain their interest. The first year engineering students at KLE Technological University undergo a 3 credit laboratory course on engineering drawing i.e. Computer Aided Engineering Drawing (CAED). This course involves manual drawing augmented with learning a drafting tool. Problem-based learning (PBL) approach, a promising new teaching approach which fuels the students learning capabilities is gaining attention of many leading technological universities. This PBL approach is introduced in teaching the CAED and the reactions are studied. Drawing standards and techniques were taught manually. After introducing PBL approach in our course and looking into the learners responses, we see improvement in the interest level of students and also in nurturing the skills required to address the problem. A real-world problem involving a route map was given to the students before teaching the drawing standards and students were asked to solve the problem. After teaching the basic of engineering drawings, the real-world problem was updated to a complex problem. Students provided solution with lot of curiosity and attentiveness. This facilitation of student friendly teachinglearning environment is most desired by any academician. The PBL approach to teach a technical drawing course is quite interesting not only for the learners but also for the instructors. The optimal PBL teaching approaches to these kinds of courses need more careful implementation steps. This small attempt to impart the drawing standards to learners using PBL route is successful looking into their responses to the problems.
\end{abstract}

Keywords: Engineering drawing, PBL.

\section{Corresponding Author}

Shreeshail M. L., Assistant Professor, School of

Mechanical Engineering, KLE Technological University, Hubli, Karnataka - 580031, India.

shreeshail_m@kletech.ac.in

\section{Introduction}

Attention, active engagement, feedback and consolidation are the four learning pillars. Catching the student's interest level in the first student interaction is the job of a teacher (Sanjeev M. Kavale et al., 2017). The student's active participation is required to learn new things and if any error occurs, one has to learn from that mistake which academician call it as error feedback learning (Arun Y. Patil et al., 2016). The learning can be measured by qualitatively and quantitatively (Chalageri and Raju, 2015). The imagination power in the engineering field is limitless (Elyan et al., 2020). Engineers have to convey their imagination to a second person with the help of technical drawings (Chang, 2012). Learning the engineering drawing is crucial as it is also called as basic language of an engineer (Rica et al., 2020). Learning and practicing the engineering drawing are possible in the traditional way i.e. manual drawings and then through any software drafting tools. But students have a casual impression that the drawing courses are simpler and easier. The fact is that the perfect engineering drawing is always simple to read and understand than the formal English language description. However, to read an engineering drawing one has to create it first (Shreeshail and Koti, 2016). To learn this technical drawing and improvise the interest level, a problem based learning (PBL) activity is introduced in the engineering drawing course (Hussain et al., 2019). The PBL activity grips the interest level of the learners in the first introductory session and from there on retains it to learn the drawing effectively. This article discusses the development of the problem, shares the experience of the teacher and study the students response to the PBL activity.

\section{Problem Development}

Conventionally, the students were acquiring the drawing standards and were learning the technical drawing related courses from sources like reference text books, scheduled component drawings as per the course plan, assignments, i.e. almost converting the printed textbook sheets to manually drawing sheets (Young et al., 1994). Before teaching the drawing basics to the students, a PBL associated activity was introduced. This activity was named as 'route map' activity. While planning this activity, three aspects have been considered. They are activity must resonate creativity and yet be simple, activity should be inclining to the course content and the activity should be pedagogically sensible (Kapur, 2015). The involvement of the students in the activity was reflected in the response they portrayed during drawing by creating their own route map. Reading the message thoroughly, executing the steps within their knowledge and full participation were the 
highlights of this activity. The outcome of this innovative route map pedagogic activity has been more satisfying in an attempt to design and assess a PBL teaching approach for a technical drawing course (Loyens et al., 2015).

The PBL activity was scheduled after the course introductory session and before the start of the CAED course teaching. A scenario was given to students with two messages in a confidential file. The scenario was that "A Defence Air Force plane in Guwahati airbase, Assam, India is scheduled for a flight to Srinagar airbase, J\&K Union Territory, India. The shortest distance is approximately $2000 \mathrm{Kms}$ with air route passing through Himalayan mountain range. The Pilot, co-pilot and the first officer are in charge of the 2 hours flight carrying a highly confidential, heavy defense consignment with an Engineer in-charge. You are now appointed as the Engineer in-charge to safely assist the transfer of the defense consignment. You are also supposed to handover the file of flight path to the pilot". This situation was briefed to the students and they were asked to assume that they are now engineer in-charge of the special flight. The two messages were given to the students, who were now acting as engineer in-charge. The First message is stated as - "Departure from Guwahati airbase at 4 AM. Permit to use New Delhi airspace. Land at Srinagar airbase at 6 AM". Then the pilot will be requesting the engineer incharge to prepare a route map with the approximate distance information at the earliest to ensure safe and secure flight journey. All students were given sufficient time of fifteen minutes to draw the route map as per the confidential file message. The two printouts of the map with three locations indicated were provided to each student. In the first print out of the map, the above route map was expected to draw. After teaching students the basics of engineering drawing, particularly line types and dimensioning elements, the second print out of the map was used for drawing the route by the students.

The change in the second message was also made for the second map. The second confidential message says "Departure from Guwahati airbase at 4 AM. Permit to use New Delhi airspace. Land at Srinagar airbase at 6 AM. Switch on the radar response system from Guwahati airbase to New Delhi airspace. Switch off the radar response system from New Delhi airspace to Srinagar airspace. Switch on the radar response system after entering Srinagar airspace". The combination of partially visible and partially hidden flight path displayed in the radar system is correlated to the visible and hidden lines of the engineering drawing line types. The students responses to both messages were recorded in the two route maps and few of them are documented in this article for the discussions. The template copy of the map with three locations indicated which were provided to all students is shown in the figure 1 .

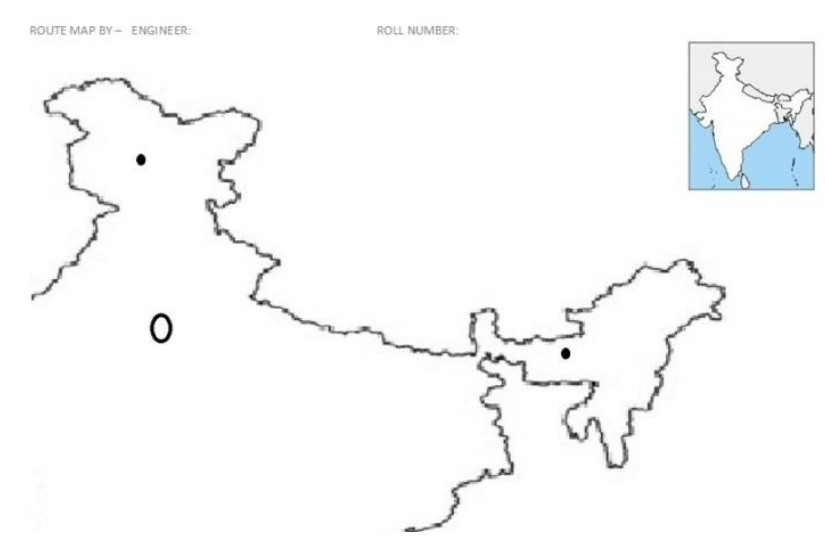

Fig. 1 Template copy of the map with 3 locations marked.

\section{Observations and Discussions}

The students are learning the engineering drawing manually and later the drawing conventions are practised using a drafting software tool. The techniques and applications of the conventions were subjected to test through this route map PBL activity. During answering the first message in the briefed scenario, students were fresh into the drawing course with just completing the introductory session. Student's response to the first confidential message was interesting. Most of them were applying their imagination into drawing a route map like some of them drew a small plane symbol, some showed radar symbol in the map. Students were left to explore their imagination limit and asked to draw it on paper for displaying a route.

The drawings of four students were considered for the evidence and discussions. They were named as student 1 , student 2 , student 3 and student 4 . In the figure 2 , student 1 drawing is scanned and this was before the drawing instructions were given to them. Student 1 imagined and drew the route map with a small plane symbol from Guwahati airbase to New Delhi airspace route. Looking into the drawing one can easily say that apart from a pencil, student 1 has not used any other drawing instrument to draw that route. Student 1 has even added the north-south-east-west direction symbol and given the distance information in the English language. However, after the drawing instructions were given to the class, student 1 learnt the line type and executed it in the next drawing. In the figure 3, student 1 drawing is scanned and this was after the drawing instructions were given to them. One optimistic change observed in the student 1 is the route from Guwahati to New Delhi is drawn with the continuous thick line which indicates the visible line as per drawing convention correlating with radar system being in on mode. Next route from New Delhi to Srinagar, student 1 has drawn a dashed line which indicates the hidden line as per drawing convention correlating with radar system being in off mode. 


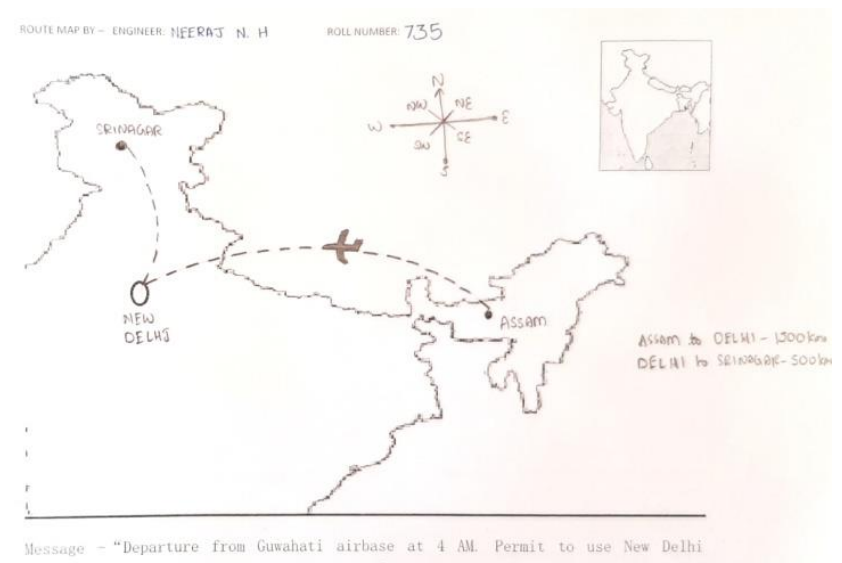

Fig. 2 Solution by Student 1 before the drawing instructions was given.

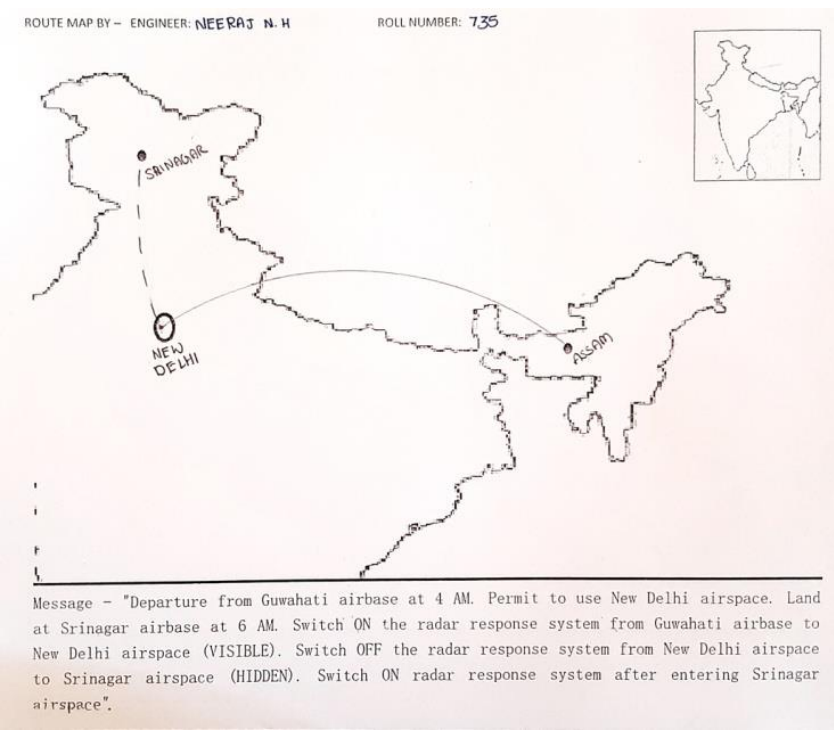

Fig. 3 Solution by Student 1 after the drawing instructions was given.

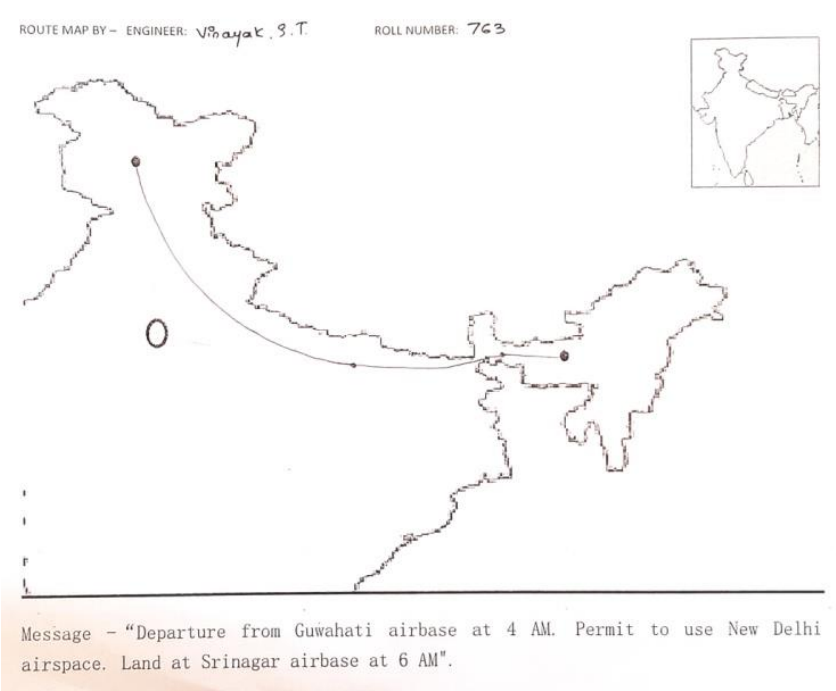

Fig. 4 Solution by Student 2 before the drawing instructions was given.

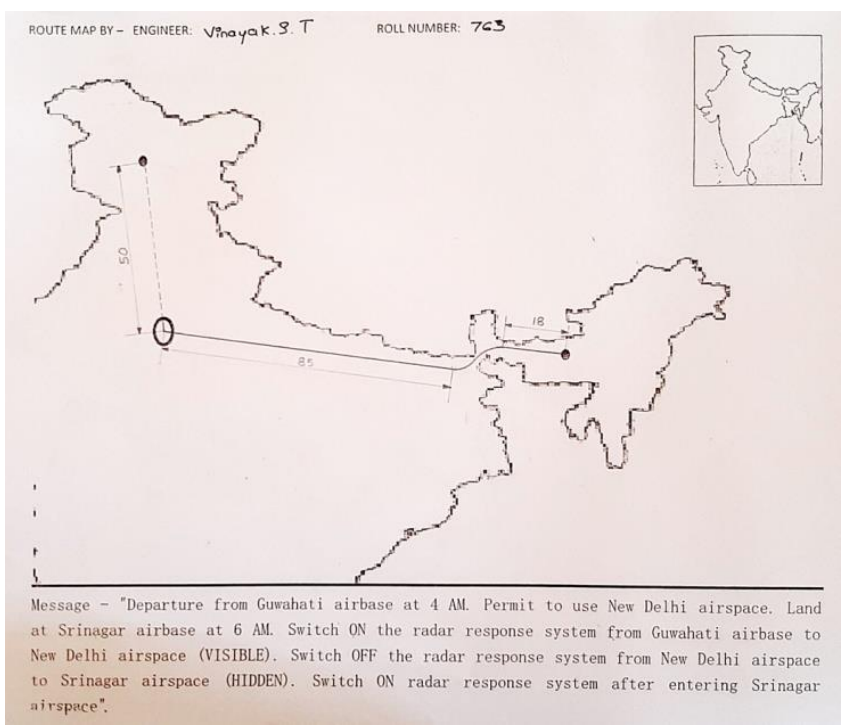

Fig. 5 Solution by Student 2 after the drawing instructions was given.

In the figure 4, student 2 has drawn the route map with a freehand continuous line and indicated the direction of travel with a small arrow head. After learning the drawing conventions, student 2 has used the scale for drawing straight lines, and compass for two arc lines. For the first segment of travel, the line type is visible line and second segment of travel is hidden line. This clearly indicates that student 2 has adapted the line type conventions depending on the situation needed. One more observation in the figure 5 is that the student 2 has annotated the lines as per the conventions giving the distance information.

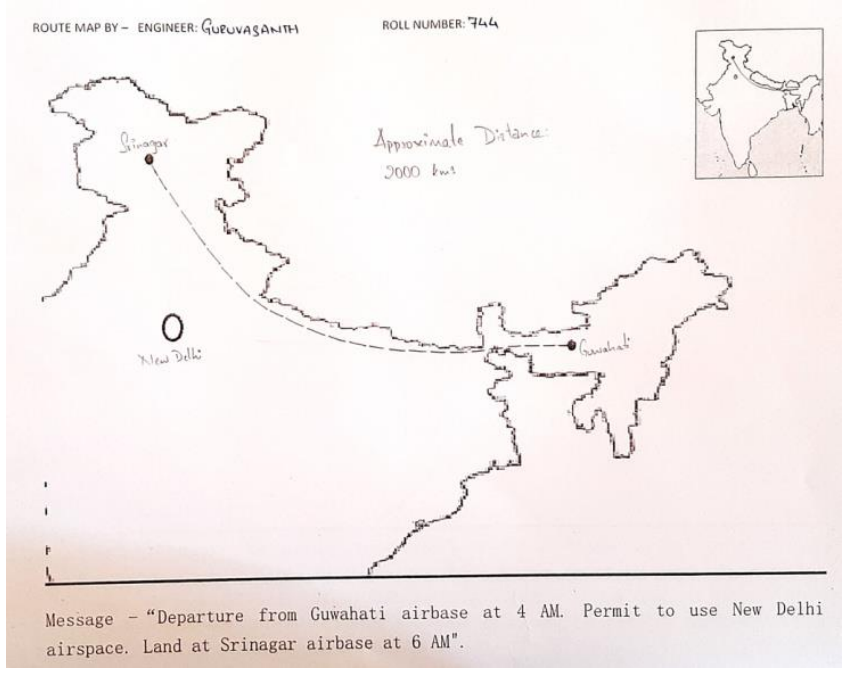

Fig. 6 Solution by Student 3 before the drawing instructions was given.

In the figure 6 , student 3 has drawn the route map with a freehand dash line and has given the approximate distance in the solution. Later, the same student 3 has drawn a visible thick line and a hidden dash line for the first and second segments of the air travel respectively. The line work in figure 7 shows the student has effectively learnt the drawing conventions and has annotated the shorter distance as per the drawing standards. 
Table 1. Assessment details of the sample students.

\begin{tabular}{|c|c|c|c|c|c|c|c|}
\hline $\begin{array}{c}\text { Sample } \\
\text { Student } \\
\text { number }\end{array}$ & $\begin{array}{c}\text { Roll } \\
\text { Number }\end{array}$ & $\begin{array}{c}\text { Experiment } \\
\mathbf{1} \text { and 2 } \\
(\mathbf{2 0} \text { marks })\end{array}$ & $\begin{array}{c}\text { ISA 1 exam } \\
\mathbf{( 1 5} \text { marks })\end{array}$ & $\begin{array}{c}\text { Experiment } \\
\mathbf{3} \text { and 4 } \\
(\mathbf{2 0} \text { marks })\end{array}$ & $\begin{array}{c}\text { ISA 2 exam } \\
\mathbf{( 1 5} \text { marks })\end{array}$ & $\begin{array}{c}\text { Experiment } \\
\mathbf{5} \\
\mathbf{( 1 0} \text { marks })\end{array}$ & $\begin{array}{c}\text { Total } \\
\mathbf{( 8 0} \text { marks })\end{array}$ \\
\hline Student 1 & 735 & 16 & 14 & 18 & 13 & 10 & 71 \\
\hline Student 2 & 763 & 20 & 10 & 18 & 14 & 10 & 72 \\
\hline Student 3 & 744 & 17 & 8 & 14 & 13 & 10 & 62 \\
\hline Student 4 & 724 & 20 & 9 & 17 & 12 & 9 & 67 \\
\hline
\end{tabular}

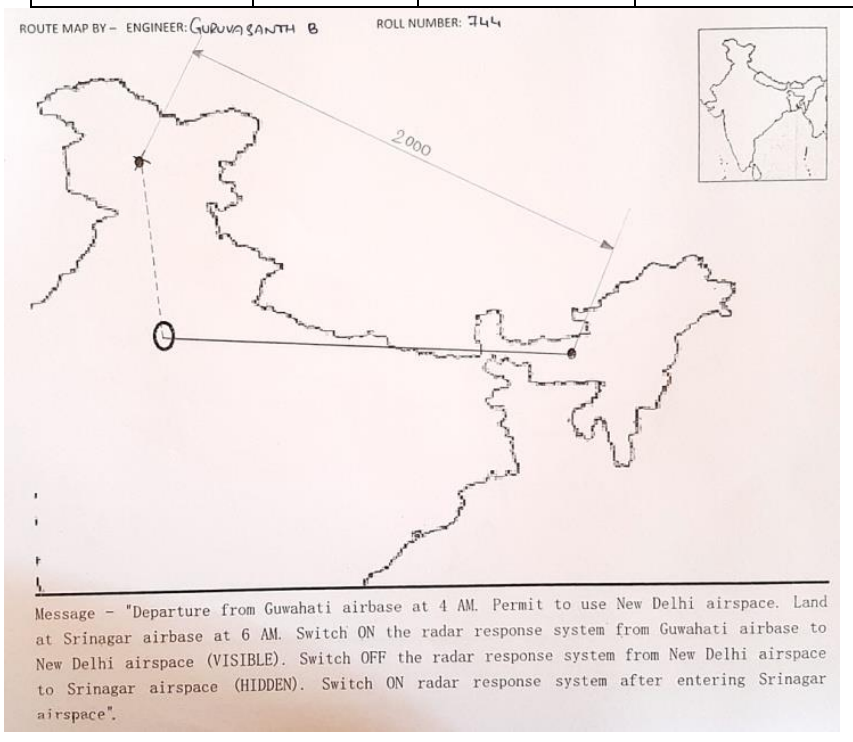

Fig. 7 Solution by Student 3 after the drawing instructions was given.

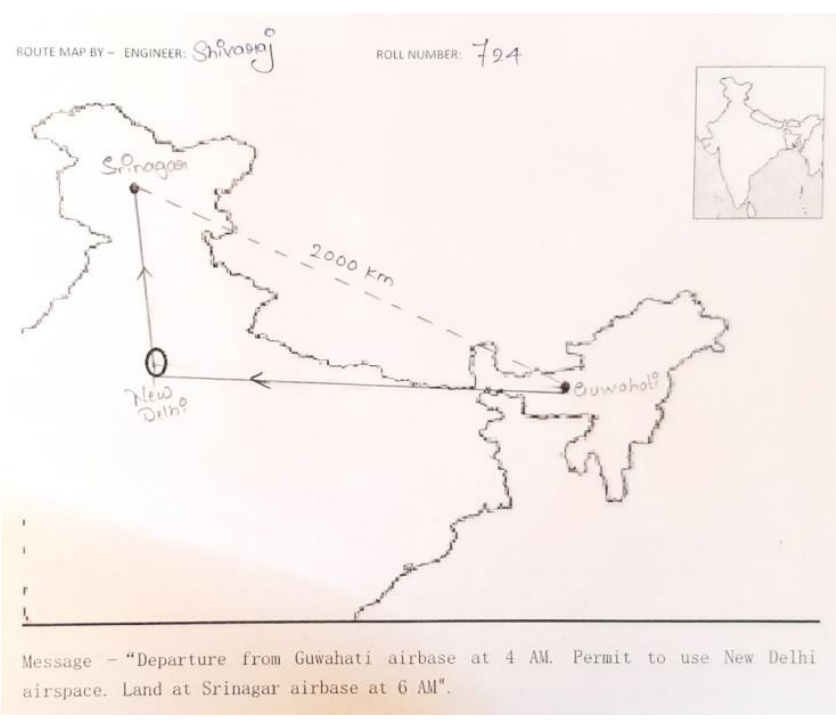

Fig. 8 Solution by Student 4 before the drawing instructions was given.

As shown in the figure 8 , student 4 has read the first confidential message and has drawn the continuous line for the air travel and has used dash line for annotating the distance. However after reading the second confidential message, student 4 has used the visible thick line for first segment and hidden dash line for second segment of air travel as shown in the figure 9.

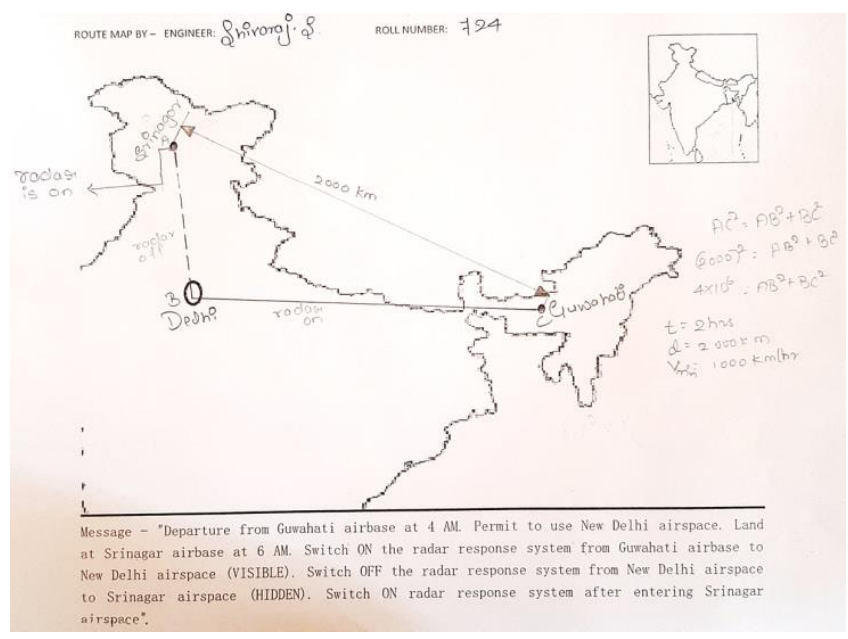

Fig. 9 Solution by Student 4 after the drawing instructions was given.

Looking into all four students drawings, the application of drawing conventions are clearly visible in all solutions which are scanned after the drawing instructions were given to them. To pick one which appeals more is the figure 5 of the student 2 drawing in which the line work and annotation work is displayed with utmost care. The assessment details with enrolled numbers of the four students are given in the table 1 . The experiment 1 and 2 with score of 20 marks is for assessing the learner's manual drawing capabilities especially line work and dimensioning conventions of representing the points, lines, planes and solids. After completing these two experiments, in semester assessment-1 (ISA -1) of 15 marks was conducted manually. The experiment 3 and 4 with score of 20 marks is for assessing the learner's drawing skills in development of surfaces and orthographic projections exercises. Then based on these two experiments, in semester assessment-2 (ISA -2) of 15 marks was conducted. Experiment 5 of 10 marks is for assessing the student's isometric drawing created from a given orthographic drawing. By the end of the semester, a student can score maximum of 80 marks with five experiments and two assessments. Due to COVID-19 pandemic and the nation was under lockdown, academic activities were shifted to online. Learning and assessment of this course from experiment 3 onwards was done in the common online platform. Looking into the positive response of students to the PBL activity and experiment 1 and 2 scored marks, similar PBL activities can be planned 
for other experiments also. As the PBL activity with a route map example reported in this article is held before the starting of experiment 1 , the effect of this activity is seen in the assessment scores of experiment 1 and 2 performances.

The significance of the PBL activity depends on the student's enthusiasm. During the informal discussions with the students, they said PBL sessions were interesting sessions and student's reaction was found to be positive. They insisted to have this kind of activity to all drawing sessions. However, we had planned this PBL activity on the route map only for the introductory sessions, which focused on the line types and elements of dimensioning. Looking into the student's response more activities can be planned for the remaining drawing sessions, especially on the orthographic projections and development of surfaces. Then it will be easier for the teacher to assess the drawing skills with quantifiable performance marks.

\section{Conclusions}

The route map activity addresses the possibility of using problem based learning approach to teach engineering drawing. Students were exposed to the problem when they were not provided with any of the drawing conventions at the start of the drawing course. Based on the students own imagination, they portrayed the solution to the problem through a route map. When students were presented with the basic drawing conventions after the completion of first problem, they were immediately exposed to an updated problem. This updated problem was then used as a basis for the creation of different route maps. This PBL approach facilitated the students to have an improvement in the interest level during the drawing course delivery. The crucial observation is that the learning grip was achieved in the initial class sessions of the course and if we have the more PBL related sessions in all of the remaining drawing sessions, then students learning will be more effective.

\section{Acknowledgement}

The authors would like to thank Dr. Ashok S. Shettar, Vice - Chancellor, KLE Technological University, Hubli, Karnataka, India and Dr. P. G. Tewari, Principal, B.V. Bhoomaraddi College of Engineering and Technology, Hubli, Karnataka, India for the encouragement and support. We like to thank technical staffs of the School of Mechanical Engineering for their support.

\section{References}

Chang C. H. (2012), Apply Discovery Teaching Model to Instruct Engineering Drawing Course: Sketch a Regular Pentagon, Procedia-Social and Behavioral Sciences, 64, 457-466.

Shreeshail M. L., and Koti C. M. (2016), Augmenting the out of Classroom Learning of Machine Drawing Laboratory Course, Journal of Engineering Education Transformations, 29(4), 37-41.
Elyan E., Jamieson L., and Ali-Gombe A. (2020), Deep learning for symbols detection and classification in engineering drawings, Neural Networks, 129, 91-102.

Young W., Daly P., and Holgate A. (1994), A problembased learning approach to civil engineering drawing, European Journal of Engineering Education, 19(2), 147-163.

Rica E., Moreno García C. F., Álvarez S., and Serratosa F. (2020), Reducing human effort in engineering drawing validation, Computers in Industry, 117, 103198.

Hussain M., Sahudin S., Samah N. H. A., and Anuar N. K. (2019), Students perception of an industry based approach problem based learning (PBL) and their performance in drug delivery courses, Saudi Pharmaceutical Journal, 27(2), 274-282.

Loyens S. M., Jones S. H., Mikkers J., and Van Gog T. (2015), Problem-based learning as a facilitator of conceptual change, Learning and Instruction, 38, 34-42.

Kapur M. (2015), The preparatory effects of problem solving versus problem posing on learning from instruction, Learning and instruction, 39, 23-31.

Arun Y. Patil, M. Shivaprasad, and Krishnaraja G. Kodancha (2016), Infusing Design Techniques-An Integrated Approach, Journal of Engineering Education Transformations, Special Issue, 2016.

Chalageri G. R., and Raju G. U. (2015), Teaching Reform through Model Building in Theory of Machine Course, Proceedings of the International Conference on Transformations in Engineering Education, Springer, New Delhi, 379-384.

Sanjeev M. Kavale, Adarsh Patil, Mantesh Choukimath, and Basangouda Shivalli (2017), Tinkering to FabricatingDeveloping Basic Skills of Fabrication in Freshmen, Journal of Engineering Education Transformations, Special Issue, 2017. 